\title{
ECTD Product Name Type Terminology
}

National Cancer Institute

\section{Source}

National Cancer Institute. eCT D Product Name Type Terminology. NCI Thesaurus. Code C97185.

Terminology developed to support eCT D Product Name Types. 